\title{
Glenohumeral Eklem Osteoartriti: Primer ve Sekonder Nedenler
}

\section{Glenohumeral Osteoarthritis: Primary and Secondary Causes}

\author{
Banu KURAN, Jülide ÖNCÜ \\ Şişli Etfal Eğitim ve Araştırma Hastanesi, Fizik Tedavi Kliniği, Istanbul, Türkiye
}

\section{Özet}

Omuz eklemi; aksiyel iskelete bağlıdır ve yapı olarak bir yandan her yere özgürce ulaşabileceğimiz kadar mobil, diğer yandan yüklenebileceğimiz kadar stabildir. Vücuttaki en geniş eklem hareket açıklığına sahip olup; aynı zamanda da glenoid ve humerusun birbiri ile uyumu sayesinde kompresyon (sıkıştırıcı) ve distraksiyon (çekme) kuvvetlerine dayanıklı bir eklemdir. Glenohumeral eklem osteoartriti primer olarak nadir olup daha çok sekonder nedenlere bağlı olarak ortaya çıkar. Bu derlemede öncelikle glenohumeral eklemin fonksiyonel anatomisinden, daha sonra da glenohumeral eklem osteoartritine neden olan hastalıklardan bahsedilecektir. Türk Fiz Tıp Rehab Derg 2012;58:236-42.

Anahtar Kelimeler: Glenohumeral; osteoartrit

\section{Summary}

The shoulder joint is attached to the axial skeleton. It is freely mobile as we can reach anywhere, while it is very stable as well. This joint has the widest range of motion in the body and it is resistant to compression and distraction forces owing to the compatibility between the glenoid and the humerus. Primary osteoarthritis of the glenohumeral joint is rare and occurs mostly due to secondary causes. In this review, glenohumeral joint functional anatomy and the diseases which cause glenohumeral joint osteoarthritis are described. Turk J Phys Med Rehab 2012;58:236-42.

Key Words: Glenohumeral; osteoarthritis

\section{Giriş}

\section{Fonksiyonel Anatomi}

Omuz eklem kompleksi; birbiriyle uyum içinde çalışan sternoklavikuler, akromioklaviküler, glenohumeral ve skapulotorasik olmak üzere başlıca dört eklemden oluşur, bu nedenle omuza ait bozuklukların tedavisinde bu eklemlerin tümü göz önünde bulundurulmalıdır $(1,2)$. Glenohumeral eklem bilyasoket tipi bir eklem olması ve geniş hacimli eklem kapsülüne sahip olması sebebiyle geniş bir hareket kabiliyetine sahiptir. Geniş hareket yeteneği nedeniyle "enartroz" yani her yönde hareketli eklem olarak da adlandırılır (1). Buna karşılık eklem temas yüzeylerinin uyumunun bozulmaması için eklem hareketi belli ölçülerde sınırlandırılmıştır (constrained) ve bu durumun ahafif translasyona yol açtığı bilinmektedir (2).

Omuz kuşağı, proksimal ve distal olarak iki komponente ayrılır (1). Proksimal komponent, skapula ve glenoidden oluşur; glenoid kavite yoğun fibokartilajenöz yapıdaki labrumla kaplıdır. Labrum, soketin derinliğini \%50 arttırmakta ve humerus başına stabilite kazandırmaktadır (1). Glenoid kavite, labrumla birlikte ekleme supero-inferior (dikey) yönde yaklaşık $9 \mathrm{~mm}$; anteroposterior (yatay) yönde de yaklaşık $5 \mathrm{~mm}$ derinlik kazandırır (2). Labrum lezyonu olan 140 hasta üzerinde yapılmış bir çalışmada; omuz 90lik abdüksiyondayken sıkıştırıcı yönde yük 
uygulandığında labrumun kontakt stresin etkili bir şekilde dağılımına yardımcı olduğu gösterilmiştir (3). Distal komponent ise, humerus başı ve glenohumeral eklemi içine alır (2). Humerus başı konveks ve yaklaşık $35^{\circ}$ retrovert yapıda olup; bu retroversiyon dış rotasyonu kolaylaştırır (2) (Şekil 1). Glenohumeral eklem yüzeylerinin birbiriyle temasındaki uyum, instabilite açısından önemlidir. Glenoid, ters virgül şeklindedir ve üst kısmı alta göre daha dardır. Humerus başında kıkırdak yüzeyi; hareket genişliğinin $160^{\circ}$ sini kapsamakta olup; glenoid kavitede

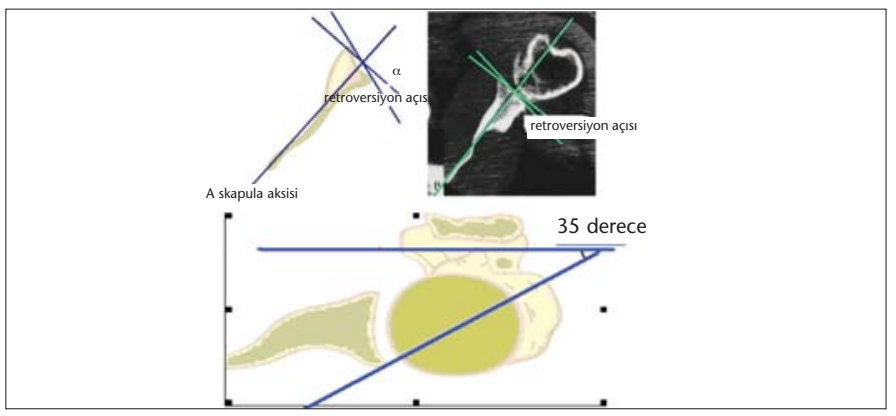

Şekil 1. Humerus retroversiyon açısı.

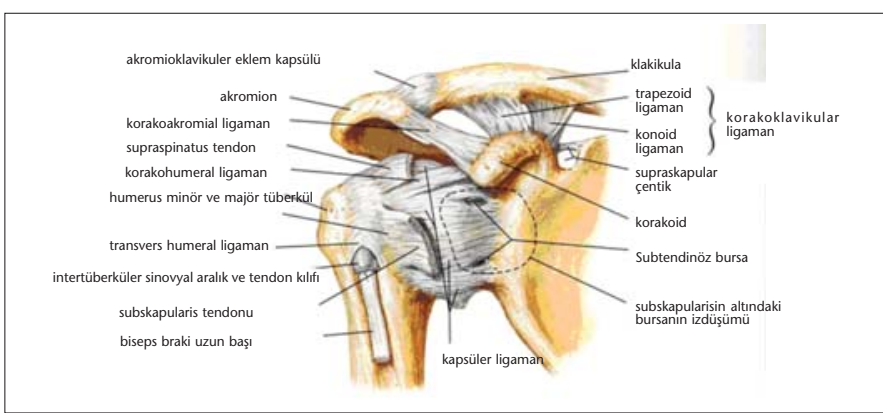

Şekil 2. Omuzun stabilizatörleri.

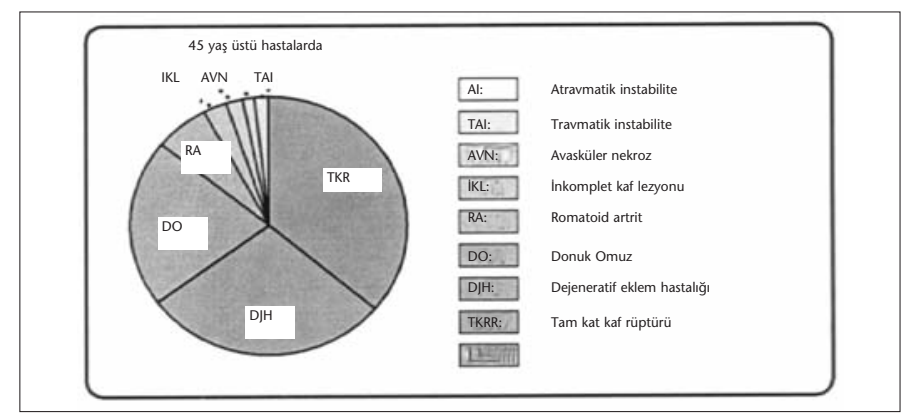

Şekil 3. Glenohumeral osteoartrit nedenleri.

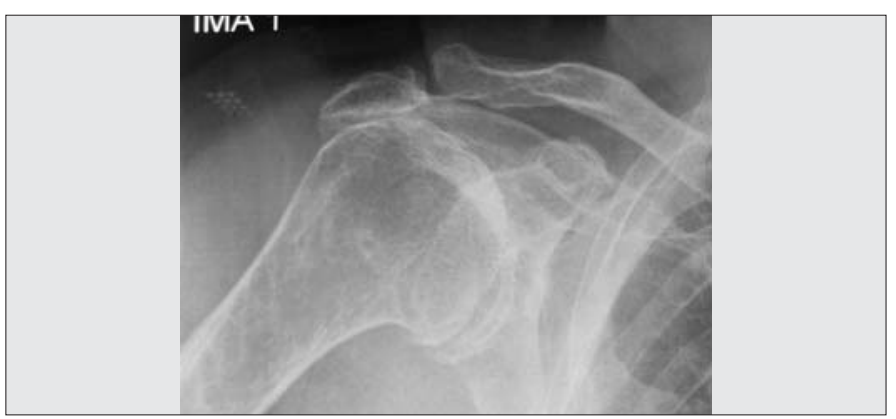

Şekil 4. GHE OA radyolojik bulguları. ise kıkırdak $75^{\circ}$ ve $95^{\circ \prime}$ dir yani geri kalan $85^{\circ}$ ve $65^{\circ}$ glenoid tarafından kapsanmamaktadır $(1,2)$ (Şekil 2). Yapılan bir çalışmada, eklem hareket açıklığı sınırlarındaki hareketlerde humerus başının sadece \%25-30'unun glenoidle sürekli temas halinde olduğu belirlenmiştir (3).

Omuzda stabilite, kemik yapılardan çok omuz kuşağı kasları ve ligamanları tarafından sağlanmakta olup; korakoakromial, korakohumeral ve glenohumeral ligamanlar omuz kuşağının primer stabilizatörleridir (1). Superior glenohumeral ligaman, $0^{\circ}$ lik abdüksiyonda glenohumeral eklemin inferiora subluksasyonunu kısıtlar ve O'Brien'a göre, ön-arka yöndeki streslere karşı omuzun stabilizatörüdür (2). Warren ve Harryman'a göre superior glenohumeral ligamanın güçlendirilmesi, inferior ve posteriora subluksasyonu önler (2). Orta glenohumeral ligaman $90^{\circ}$ in altındaki abdüksiyon derecelerinde eksternal rotasyonu kısıtlar. İnferior glenohumeral ligaman $45^{\circ}$ in üstündeki abdüksiyonda en önemli stabilizatördür (2).

Omuz kasları; ekstrensek ve intrensek olarak iki gruba ayrılır. Ekstrensek grup olarak adlandırılan romboid, levator skapula, trapezius ve serratus anterior kasları skapula kontrolünü sağlar $(1,2)$. Intrensek kas grubu ise SITS başharfleri ile hatırlanan subskapularis, supraspinatus, infraspinatus, teres minördür. İntrensek kaslar glenohumeral kontrolü sağlarlar (1,2). Deltoid, pektoralis major, teres major, latissimus dorsi ve biseps intrinsek kas grubunu oluşturan diğer kaslardır (2).

Omuzun dinamik ve statik stabilizatörleri kadar; eklemi bir arada tutan kuvvetler de önemlidir (1). Sinovyal sıvıdaki moleküler çekim, glenoid fossadaki negatif çekim, sinovya ile sıvı arasındaki negatif basınç eklemi bir arada tutan diğer etkenlerdir. Yapılan çalışmalarda, glenohumeral basınç azaldığında humerus başının 10 mm kadar aşağı düştüğü gösterilmiştir (1).

\section{Glenohumeral Eklem Osteoartriti}

Glenohumeral Eklem Osteoartriti (GHE OA), omuzun artiküler kartilaj başta olmak üzere, eklem kapsülü ve kemik yapılarının, mekanik ve biokimyasal süreçleri içeren, ilerleyici dejeneratif hastalığıdır (4). Artiküler kıkırdak yüzey yıprandıkça, eklem yüzlerinde friksiyon artar ve giderek subkondral kemikte yeniden yapılanma (remodeling) olur, humerusun sferik yapısı bozuldukça eklem bütünlüğü de bozulur; eklem kapsülü giderek kalınlaşır ve eklem rotasyonu kısıtlanır (5). Sonuç olarak, yük binen yüzeylerin aşınmasının ilerlemesine bağlı olarak, ağrı ve dizabilite ortaya çıkar $(4,5)$.

\section{Epidemiyoloji}

GHE OA; kalça ve diz gibi yük binen eklemlerin osteoartritine göre daha nadir görülür; ancak en az yük binen eklemler kadar sakatlığa yol açması sebebiyle önemlidir. Giderek şiddetlenen ağrı, günlük yaşam aktivitelerinde kısıtlanma; depresyon, anksiyete, işte ve günlük aktivitelerde performans kaybına yol açar (5). Prevalans erkeklerde 45 yaş üstünde, kadınlarda 55 yaş üstünde giderek artış gösterir ve 60 yaş üstünde $\% 32,8$ oranındadır $(5,6)$. Yaş, cinsiyet, genetik faktörler; öyküde, travma, eklem enfeksiyonu, omuz dislokasyonunun bulunması, ağır işlerde çalışma ve başüstü aktivitelerinin fazla yapıldığı 
sporlar risk faktörleri arasındadır (5). Etyolojik açıdan bakıldığında GHE OA'nın nedenleri primer ve sekonder olarak iki kategoriye ayrılır $(5,6)$. Primer GHE osteoartriti, sekonder osteoartrite göre daha nadir ve kadınlarda daha sık; sekonder osteoartrit ise erkeklerde daha sıktır (6). Hastaların çoğu 60 yaş üzerinde olup; instabilite olanlarda $30-40$ 'lı yaşlarda da ortaya

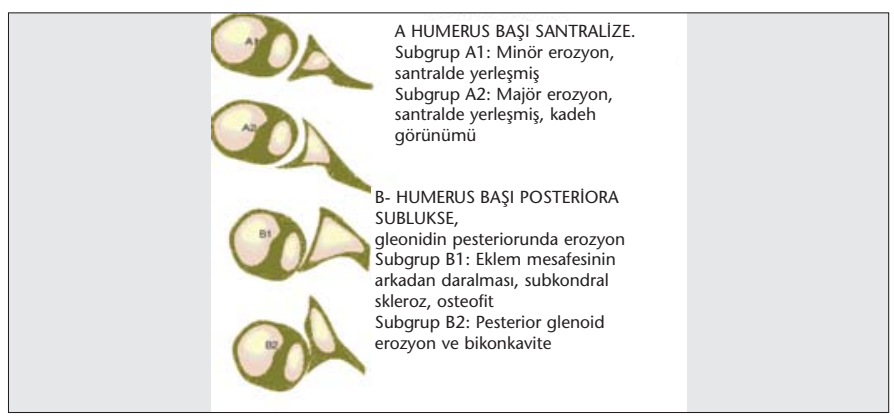

Şekil 5. Walsch Sınıflaması.

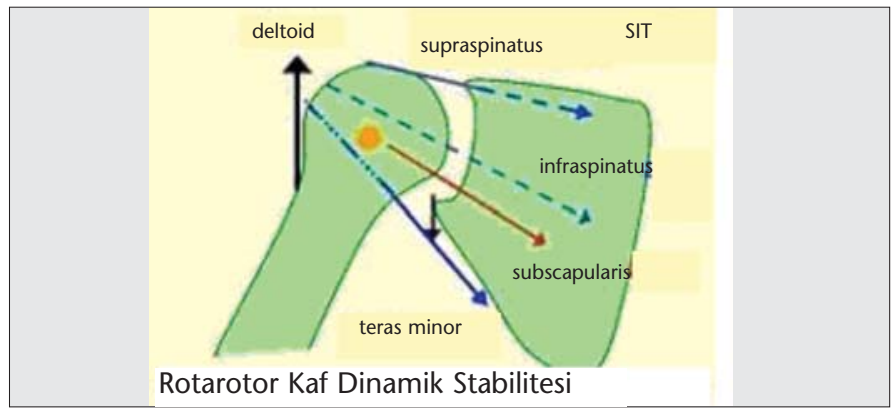

Şekil 6. Rotator kaf kasları.

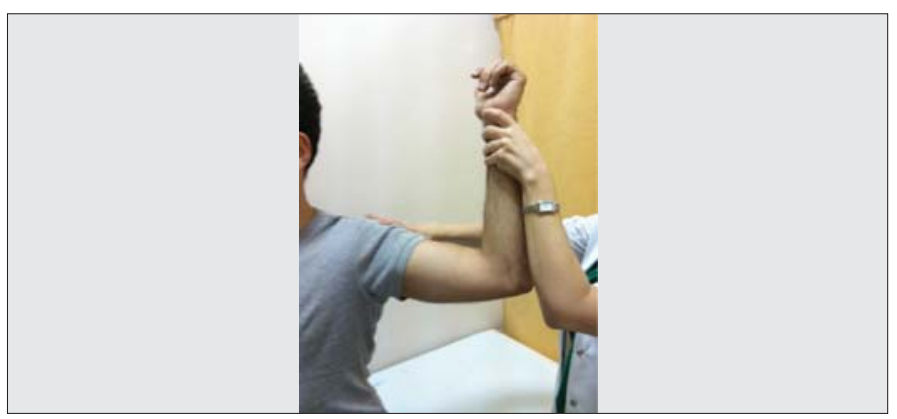

Şekil 7. Boru çalma işareti.

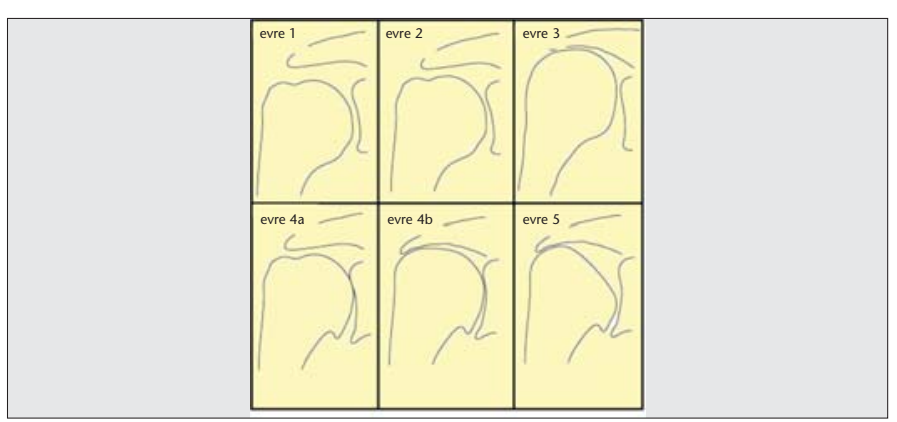

Şekil 8. Kaf tear artropati.

Evre 1: Akromiohumeral aralık $>6 \mathrm{~mm}$

Evre 2: Akromiohumeral aralk $<6 \mathrm{~mm}$

Evre 3: Akromiohumeral $<6 \mathrm{~mm}$ ve akromionda konkavite (asetabulizasyon)

Evre 3: Akromiohumeral $<6 \mathrm{~mm}$ ve akromionda konkavite (asetabulizasyon)
Evre 4a: Akromiohumeral $<6 \mathrm{~mm}$ ve glenohumeral artrit ; asetabulizasyon yok

Evre $4 \mathrm{~b}: 4 \mathrm{a}+$ asetabulizasyon ve glenohumeral artrit

Evre 5: Humerus başında kollaps çıkabilir (6). Kırk beş yaş altında inkomplet rotator kaf lezyonu, travmatik/atravmatik instabilite ve donuk omuz en sık ilk üç nedendir; 45 yaş üstünde ise tam kat rotator kaf yırtığı, dejeneratif eklem hastalığı ve donuk omuz en sık görülen nedenler arasındadır (7) (Şekil 3). Tablo 1'de, GHE OA yapan nedenler görülmektedir (7).

Primer Glenohumeral Eklem Osteoartriti

Primer $\mathrm{OA}^{\prime}$ da genellikle glenoid kavite, daha az oranda da humerus başı etkilenir (7). Semptomlar uzun bir dönemde yavaş yavaş gelişir; hastalar yıllardır süren ve giderek şiddetlenen omuz ağrısından yakınırlar (6). Genellikle pozisyonel bir gece ağrısı vardır ve üzerine yatmakla şiddetlenir (6). Ağrı, omuzda ve skapular bölgede hissedilir, eklem hareketleri ile $\operatorname{artar}(6,7)$. Eklem hareketlerinde giderek kısıtlılık oluşur, özellikle anterior yapıların gerginliğine bağlı olarak eksternal rotasyon hareketleri en fazla etkilenir; eklemde kıkırdak kaybı ve osteofit oluşumuna bağlı olarak hastalar, kolun hareketi ile omuzda sürtünme ve krepitasyon hissinden yakınırlar $(7,8)$. Bazı durumlarda; radyografik olarak belirgin dejenerasyon saptanmasına rağmen hastanın fazla şikayeti olmayabilir; ağrıdan ziyade günlük aktivitelerde hareket kısıtıılı̆ı yakınması ile başvurabilirler (8). Fizik muayenede glenohumeral eklem hareketi ile krepitasyon saptanır; eklem aralığı hassasiyeti ve pasif eklem hareket açıklığında kısıtııık bulunur (8). Kas gücü tamdır. Tanı; direkt

\section{Tablo 1. Glenohumeral eklem OA nedenleri.}

Glenohumeral osteoartritin etyolojisi

\begin{tabular}{|c|c|}
\hline Tip & Etyoloji \\
\hline PRIMER & Bilinmiyor \\
\hline \multicolumn{2}{|l|}{ SEKONDER } \\
\hline \multirow[t]{9}{*}{ - Atravmatik } & Alkol \\
\hline & Kortikosteroid \\
\hline & Sitotoksik ilaçlar \\
\hline & Gaucher hastalı̆̆ı \\
\hline & Lipid metabolizma hastalıkları \\
\hline & Obezite \\
\hline & Radyasyon \\
\hline & Orak hücre anemisi \\
\hline & - $\quad$ osteonekrozis \\
\hline \multirow[t]{4}{*}{ - Enflamatuar } & Kristal artropati \\
\hline & Postenfeksiyöz artropati (tbc...) \\
\hline & Romatoid artrit \\
\hline & Rotator kaf artropati \\
\hline \multirow[t]{3}{*}{ - Cerrahi sonrası } & Kapsulorafi sonrası (anterior eklem \\
\hline & kapsülünün aşııı gerilmesi) \\
\hline & Metalik implant sonrası \\
\hline \multirow[t]{3}{*}{ - Travmatik } & Dislokasyon, subluksasyon \\
\hline & Proksimal humerus kırı̆̆ı malunion \\
\hline & Postravmatik avasküler nekrozis \\
\hline \multirow[t]{3}{*}{ - Konjenital } & Epifizer displazi \\
\hline & - $\quad$ Akromegali \\
\hline & - $\quad$ Kollajen bozuklukları \\
\hline
\end{tabular}


grafi ile konur. Omuz ekleminin incelenmesinde pratikte kullanılan standart grafiler; gerçek anteroposterior grafi (Grashey grafisi: kol 45' internal rotasyonda); lateral skapular (skapular outlet) ve aksiller (kol abdüksiyonda kaset superiorda) grafilerdir (9). Direkt grafide, glenoid ve humerus başında inferiorda osteofit görülmesi klasik radyolojik bulgudur (Şekil 4). Osteofitin büyüklüğü de osteoartritin şiddeti ile ilişkilidir; ileri osteoartritlerde osteofitler $7 \mathrm{~mm}$ den büyüktür (10). Zamanla,

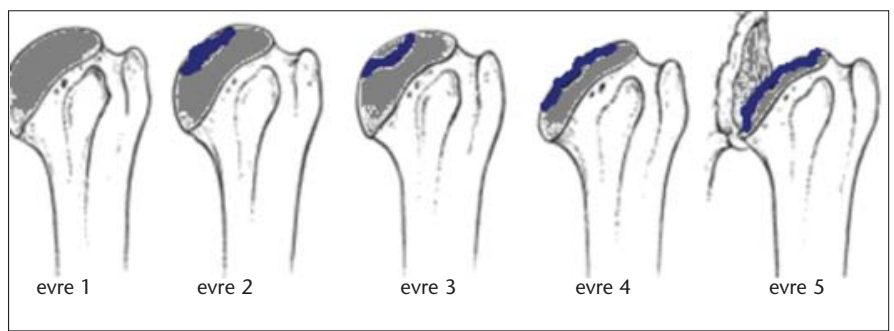

Şekil 9. Cruess sınıflaması.

Evre 1: Radyolojik görünüm yok, MRl,sintigrafi, biopsi gerekir Evre 2: Subkondral osteoliz/kistler;

Evre 3: Subkondral kırılma, osteoskleroz "yarım ay" görünümü Kemikte kollaps, kıkırdak ile nekrotik subkondral kemik arasında boşluk

Evre 4: Sağlam kıkırdak alttaki kemiğe yeniden tutunur ama humerus başı artık küresel değildir Evre 5 : Humerustaki şekil bozukluğu glenoidi de bozar.

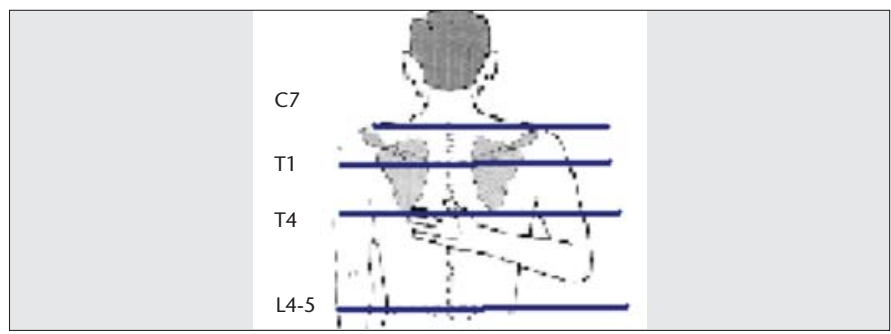

Şekil 10. Apley kaşınma testi.

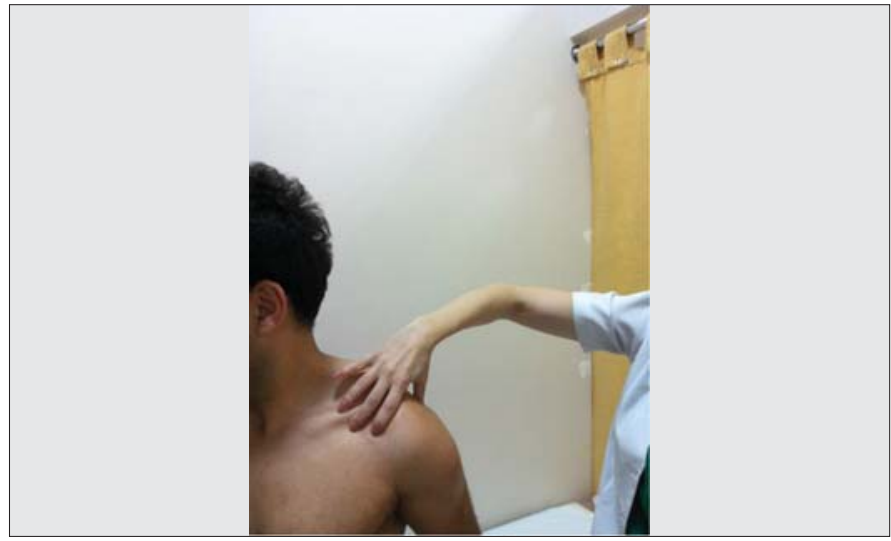

Şekil 11. Korakoid testi.

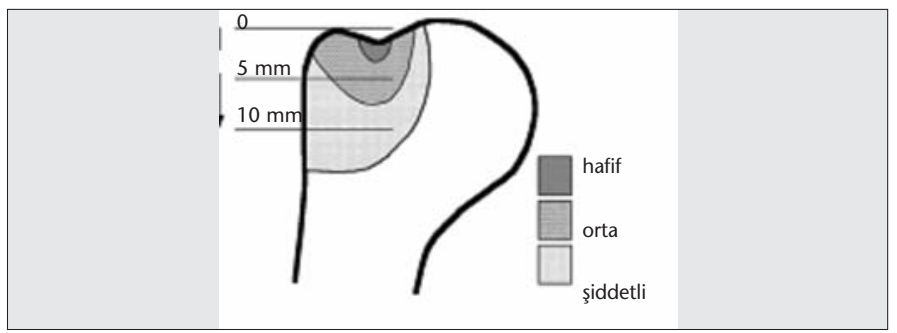

Şekil 12. Romatoid artritte erozyon şiddeti. eklem aralığında düzensizleşme ve daralma, humerus başında subkondral kistik değişiklikler, glenoid posteriorunda erozyon meydana gelir. Subkondral skleroz ve kistik değişiklikler humerus başı superolateralinde ve glenoidin santral kesiminde meydana gelir (4). Bu bölge kolun $60^{\circ}$ ile $100^{\circ}$ lik abdüksiyonu arasındaki iki eklem yüzeyinin maksimum temas ettiği bölgedir. Aksiller grafiler, eklem aralığı daralmasının saptanması ve posterior humerus subluksasyonunun araştırılması yönünden en iyi grafilerdir (5). Ayrıca $45^{\circ}$ abdüksiyonda çekilmiş gerçek anteroposterior grafiler de erken dönemde eklem aralığındaki daralmayı gösterebilir (5). Rotator kaf patolojisi düşünülüyorsa MRG istenebilir; hastaların 5\%'inden azında rotator kaf yırtığı bulunmaktadır (1).

Glenoidde retroversiyon, subkondral kistler ve humerusun posteriora subluksasyonu varlığında operasyon kararı açısından hasta bilgisayarlı tomografi ile değerlendirilmelidir (6). Glenoid morfolojisi ve humerus başı ile ilişkisi hem primer osteoartrit gelişim riski açısından hem de cerrahi açıdan önemlidir (6). Glenoid retroversiyon açısı normalde $25^{\circ}$ olup; $45^{\circ}$ nin altında anterior; $55^{\circ}$ nin üstünde posterior subluksasyon meydana gelir (11). Walch tarafından yapılan tanımlamaya göre, humeral başın statik posterior subluksasyonunun osteoartrit gelişiminde öncül olduğu ve posterior subluksasyonun, artritin ilk radyografik bulgusu olabileceği bildirilmiştir (11). Primer GHE OA gelişiminde glenoid morfolojisi ele alınarak Walch tarafından bir sınıflama yapılmıştır ve günümüzde de halen ortopedistler tarafından bu sınıflandırma kullanılmaktadır (12) (Şekil 5).

\section{Sekonder Glenohumeral Eklem Osteoatriti}

\section{Rotator Kaf Artropatisine Sekonder Gelișen Glenohumeral}

Osteoartrit

Rotator kaf omuzdaki stabiliteyi sağlayan çok önemli bir yapıdır (1). Örneğin; fırlatma aktiviteleri sırasında omuzdaki distraksiyon kuvveti (çekme kuvveti) vücut ağırlığının \%75'i kadar olup; bu esnada rotator kaf tendonları, humerus başını eklemde tutabilmek için deltoid ile beraber kuvvet dengesi oluşturur, üstteki deltoidin kuvveti, alttaki rotator kaf kasları tarafından dengelenir (1) (Şekil 6).

GHE osteoartritinde rotator kaf lezyonu \%76-92 arasındadır (13). Omuz ekleminde yaşlanma kıkırdaktan değil tendondan başlar (13). Kadınlarda erkeklerden daha fazla; dominant ekstremitede non-dominant ekstremiteden daha fazla görülür (14). Rotator kafın akut yırtığı, travma sonrası ve gençlerde daha sıkken; kronik yırtık yaşlılarda daha sık görülür (14). Hastaların çoğunda giderek artan ağrı ve omuz hareketlerinde kısıtlanma, gece ağrısı ve kas güçsüzlüğü yakınmaları vardır (14).

\section{Tablo 2. Larsen sınıflaması.}

Evre $0 \quad$ Normal eklem aralığı

Evre $11 \mathrm{~mm}>$ çaplı erozyon veya eklem aralığı daralması

Evre $21 \mathrm{~mm}<$ çaplı bir veya daha fazla küçük erozyon

Evre 3 Belirgin erozyon

Evre 4 Ciddi erozyon (genellikle eklem aralığı kalmamıştır ve orijinal kemik sınıların sadece bir kısmı korunabilmiştir

Evre 5 Ileri destrüktif değişiklikler 
Rotator kaf yırtıkları eğer küçük çaplı ise semptomatik olmayabilir. Masif yırtıklarda ise kaslarda kronik miyotendinöz retraksiyon ve yağlı infiltrasyon sonucunda kas güçsüzlüğü, humerus başının superiora subluksasyonu sonucu hareket kısıtlıı̆ı ve bunların etkisiyle eklem aralığında osteoartrit meydana gelir (15). Masif rotator kaf yırtığı, en az 2 majör tendonun yırtığı ya da yırtığın ön-arka çapının $5 \mathrm{~cm}$ den büyük olduğu rüptürler olarak tanımlanmaktadır (15). Tam kat yırtık sonrasında GHE osteoartriti gelişiminde iki mekanizma etkilidir (14). Birincisi mekanik olarak instabilite meydana gelmesi, ve tekrarlayan travma sonucu eklemin dejenere olması; ikincisi ise sinovyal sıvının subakromiyal bölgeye sızarak eklem içi basınçta azalma olması ve besin perfüzyonunun bozulmasıdır (14). Fizik muayenede "eksternal rotasyonda sarkma testi" infraspinatustaki yırtığı gösterir (16). Test sırasında hastanın omuzuna pasif olarak maksimum dış rotasyon yaptırılır ve sonra hastanın omuzunu bu pozisyonda tutması istenir (16). Hasta aktif olarak pozisyonu koruyamazsa infraspinatus yırtıktır (16). "Boru çalma işareti"nde ise dirsek desteklenir, hastanın kolunu dış rotasyonda tutması istenir; eğer tutamazsa teres minör kası yırtılmış demektir (16) (Şekil 7).

Direkt grafide; humerusun yukarıya migrasyonu, glenoid üst ucunda erozyon, humerus başı superolateralinde subkondral kistler ve düzensizlik, eklemde daralma, glenoidde fragmantasyon ve ileri evrelerde humerus başında çökme görülür (14). "Kaf yırtığına bağlı artropati" adı verilen bu durum sonucunda humerus başında yükselme, akromioklaviküler eklemde daralma, akromionda "asetabulizasyon" ve humerus başında yuvarlaklaşma yani "femoralizasyon" meydana gelir (6). Kaf artropatisinde diğer bir radyolojik bulgu kaş (sourcil) işaretidir. Humerus başı yukarı doğru yer değiştirdikçe, akromionun alt tarafında da erozyon ve aynı zamanda humerusun inferiorunda da osteofit ve eklem aralığında daralma meydana gelir (17) (Şekil 8). Glenoidde erozyon ve yük binen yerlerde kanca tipi osteofit gelişmesi de rotator kaf patolojisine sekonder gelişen değişikliklerdendir (17).

Kronik zeminde akut gelişen yırtıkların ve masif rotator kaf yırtıklarının tedavisi oldukça zordur. Rotator kaf yırtığının büyüklüğü, cerrahi sonrası kötü klinik sonuçla doğrudan ilişkilidir (15). Yağlı infiltrasyon ve humerusun kraniale migrasyonu sonucu akromiohumeral mesafe $7 \mathrm{~mm}$ 'den az kalmış ise masif rotator kaf yırtıklarının ameliyat ile onarımı önerilmez (15).

Masif kaf yırtıklarında tedavi cerrahi yöntemlerle yapılır. Ancak normalde 7-14 mm arasında olan subakromial mesafe 7 mm'nin altında ise onarım başarısız olur (15). Ayrıca; supraspinatus ve infraspinatusta Evre 4, subskapulariste Evre 2 yırtık varsa ve MRG'de T1 imajda supraspinatusta yağlı dejenerasyon mevcutsa ve fossanın \%50'sinden fazlası yağ ile dolu ise opere olsa dahi iyileşemeyebilir (15).

\section{Milwaukee Omuzu (Senil Hemorajik Omuz Sendromu)}

Sinovya ve kıkırdakta biriken kalsiyum hidroksiapatit ve kalsiyum pirofosfat kristalleri sonucu eklemde enflamasyon ve takiben destrüktif atropati gelişir (18). Milwaukee omuz sendromu kristal depolanması, destrüktif artropati, rotator manşon yırtığı ve eklem instabilitesi ile birlikte ilerleyici fonksiyon kaybına neden olan ağrı, şişlik gibi klinik bulgularla karakterizedir
(18). Enflamasyon kafı tahrip eder ve kristal salınımı artar. Yaşlılarda ve bayanlarda daha sık olup hızlı ve ilerleyici bir seyir gösterir (18).

Avasküler Nekroz

Omuzun avasküler nekrozu nadir olup; en sık 20-50 yaş arası erişkinlerde görülür (19). İdiyopatik (primer osteonekrozis) olarak ortaya çıkabileceği gibi travma ve kortikosteroid kullanımı başta olmak üzere sekonder nedenlere bağlı olarak da görülür (20).

Humerus başı femurdan sonra ikinci en sık tutulan bölgedir. En sık humerus başının glenoidle $90^{\circ}$ abdüksiyonda artikülasyon yapan superosantral kısmı etkilenmektedir (20). Humerus başını çevreleyen aksiller arter, posterior sirkumfleks arter ve anterior sirkumfleks arterde kan akımında engel oluşturabilecek tromboembolizm, staz ve vazospazm gibi çeşitli mekanizmalar sonucunda oluşur $(20,21)$. Risk faktörleri arasında; steroid kullanımı, orak hücre anemisi, travma, Gaucher's hastalığı, Caisson hastalığı, radyasyon öyküsü, alkolizm, kanser, lupus gibi otoimmun hastalıklar yer almaktadır (21). Oral kortikosteroidler adipoz doku hipertrofisini arttırarak, serum lipid içeriğini yükseltir. Bunun sonucunda mikroskopik yağ embolileri kemikteki endarterlerin tıkanmasına ve kemik içi basıncın artmasına neden olur. Ayrıca intraartiküler uzun etkili kortikosteroid enjeksiyonlarının multifokal osteonekroza yol açtığı da bildirilmiştir (21).

İskemiden 6-12 saat sonra kemik iliği ölümü ve subkondral kemikte nekroz meydana gelir. Radyolojik değişiklikler kemik iliği ölümünden 3 ay sonra meydana gelir. Mikro kırık ve humerus başında çökme (kollaps); hastaların \%80'inde ve 6-12 ay sonra oluşur. Bu ilk 3 aylık dönem fırsat penceresini oluşturur; nekrotik alan kollapstan önce revaskülarize olursa hastalık ilerlemez. Süreç ilerlediğinde de en son olarak kartilajda separasyon, glenoid kıkırdak kaybı ve glenohumeral eklemde osteoartrit meydana gelir (19).

Klinik olarak, başlangıçta sadece aktivite sırasında ağrı olabilir. Hastalık ilerledikçe ağrı artar, aktif ve pasif hareket kısıtlanması ve fonksiyon kaybı olur. Direkt grafi erken evrelerde normaldir ileri evrelerde bulgu verir (20). Sintigrafide erken evrede osteoblastik aktivite ve kanlanma defekti; geç evrede ise aktivitede artı̧̧ görülür (20). MRG'de T1 imajlarında kemik iliği sinyal intensitesinde azalma olup, T2 imajlarda; nekrotik ve normal kemik ara yüzeyini gösteren klasik "çift çizgi bulgusu" ortaya çıkar ve MRG sintigrafiden daha yüksek sensitivite ve spesifisiteye sahiptir $(20,21)$. Femur başı avasküler nekrozu için geliştirilmiş radyolojik klasifikasyon; daha sonra Cruess tarafından humerus başı avasküler nekrozu için adapte edilmiştir (22) (Şekil 9). Buna göre evre 1 ve 2 'de kor dekompresyon, evre 3 'te osteotomi, evre 4 ve $5^{\prime}$ te ise protez uygulanmaktadır (22).

\section{Charcot Omuzu}

Nöropatiye bağlı proksimal humerus ve glenoidin hızlı destrüksiyonudur; nadir görülür (23). Siringomyeli, alkolik nöropati, sifiliz ve cerrahi sonrası görülen nöropati ile ilişkili olarak görülebilir (23). Ağrı, şş̧̧lik, eklem hareketlerinde kısıtılık meydana gelir (23). Omuz çıkığı ile ortaya çıkabilir; ısı artışı ve eritem ile enfeksiyondan ayırt etmek zor olabilir (23). Duyusal, motor bulgular ve asimetrik üst ekstremite refleksleri saptanabilir. 
Radiografide en sık humerus başında olmak üzere eklemin her iki tarafında ileri destrüktif değişiklikler görülür. Yumuşak dokuya gömülü kemik parçaları vardır. Ayırıcı tanıda; subluksasyon, heterotopik osifikasyon, patolojik fraktür aranmalıdır. Sintigrafide sıcak lezyonlar osteomiyelitten ayırt ettirmez; MRG ise servikal bölgede sirenks ya da kistik lezyonlar açısından yardımcı olur (23).

\section{Adeziv Kapsülit}

Donuk omuz, 40-70 yaşları arasında sık görülmekle birlikte, en sık görüldüğü yaş 55'tir (24). Patolojik olarak insidans yaklaşık \%2 olmakla beraber; 49 yaş üstünde, kadınlarda (hastaların \%70'i), diabet hastalarında (5 kat artmış risk vardır), immobilizasyon, hipotiroidizm, otoimmün hastalık, travma, servikal diskopati, akut myokard enfarktüsü öyküsü olan hastalarda daha sık görülür (24).

Temel lezyon korakohumeral ligaman kontraktürü ve kalınlaşmış, kontrakte eklem kapsülüdür. İntra-artiküler volüm azalmıştır; rotator manşon ve korakohumeral ligaman kontraktürleri en önemli lezyonlar olabilir. Supraspinatus, subskapularis ve korakoid proses arası olarak tanımlanan Rotator Kaf Interval (RKi) travmaya açık bir bölge olup; kapsüler ve sinovyal enflamasyon olabilir ve bu aralıkta sıvı toplanabilir (25) (Şekil 10). Artroskopik olarak bakıldığında kapsülde sadece adezyon değil, granülasyon dokusu, RKI'de hiperemik sinovya, peteşi görünümü mevcuttur (24).

Donuk omuz etyolojik açıdan dört tipe ayrılır; idiopatik, diabetik, post-travmatik ve cerrahi sonrası (artrofibrozis) adeziv kapsülit olarak sınıflandırılabilir (25).

Klinik olarak, minör travmalar sonrası genellikle spontan olarak başlar ve giderek ağrı ile progresif fonksiyon kaybı gelişir $(24,25)$. Muayenede; aktif/pasif EHA'ın tüm planlarda kısıtlanması en karakteristik bulgudur; radikulopati ekarte edilmelidir. Karşı tarafla kıyaslandığında asimetrik eklem aralığı genişliği vardır (Apley kaşınma testi (Şekil 10). Korakoid ağrı testinde ise karşı tarafla kıyaslandığında korakoide basmakla ağrı olması pozitif bulgudur (26) (Şekil 11). Donuk omuz tanısı olan 70 katılımcıda Delphi tekniği ile 60 soruda sağlanan konsensusa göre; gece ağrısı, üzerine yatamama, hareketle ağrıda artma, 35 yaş üstünde olma, tüm yönlerde ağrı ve pasif EHA'da kayıp adeziv kapsülit düşündüren klinik bulgular olarak saptanmıştır (27).

Nadiren aynı omuzda tekrarlayabileceği gibi; hastaların \%2030'unda karşı omuzda adeziv kapsülit gelişebilir. Klinik olarak 3 faza ayrilır $(25,26)$ :

- Faz I-(ağrı fazı): 3-6 ay sürer. Hastalar giderek şiddetlenen yaygın omuz ağrısı yakınmasıyla gelir. Ağrı özellikle geceleri şiddetlenir, etkilenmiş taraf üzerine yatmakla artar. Hasta, kolunu kullanmayı azalttıkça sertlik ortaya çıkar

- Faz II-(tutukluk fazı): Hastalar omuz hareketini kısıtlayarak ağrıyı rahatlatırlar. Bu faz 4-12 ay kadar süren tutukluk fazıdır. Günlük yaşam aktivitelerini sürdürmekte zorlanırlar; erkekler pantolon arka cebine cüzdan koymakta; kadınlar sütyen iliklemede zorlanır. Tutukluk arttıkça, özellikle geceleri şiddetlenen devamlı künt bir ağrıdan ve eklem hareket açıklığının sonuna doğru şiddetlenen keskin bir ağrıdan yakınırlar

- Faz III-(çözünme fazı): Bu faz haftalar veya aylar sürer (5-24 ay); hareket arttıkça ağrı azalır. Tedavi yapılmazsa, hareketin büyük çoğunluğu geri döner; ama hasta subjektif olarak günlük yaşam aktivitelerini bir şekilde yerine getirebildiği için tamamen normale dönmüş gibi algılasa da, objektif olarak hiçbir zaman normale dönmez.

Tanıda direkt grafiler (AP, lateral skapular ve aksiller) genellikle normaldir;osteopeni görülebilir. MRG, başka patolojileri dışlamak için gereklidir. İnferior glenohumeral ligamentte anormal derecede kalınlaşma, rotator intervalde artmış sinyal intensitesi, koronal, sagital ve oblik imajlarda korakohumeral ligamanı saran yağ dokusunu baskılayan hiperintensite görülür $(24,25)$.

Tedavi genellikle konservatiftir (28). \%10'dan daha az hastada cerrahi tedavi gerekli olabilecek uzun dönem komplikasyonlar gelişebilir. Tam iyileşmenin 6 ile 18 ay kadar sürebileceği tüm hastalara söylenmelidir (28). Tedavi sonrasında, eksternal rotasyon ve abdüksiyonda $\% 50$ 'den daha fazla kısıtlanmanın bulunması, iyileşmenin tam olmadığının göstergesidir; özellikle DM hastalarında görülür (28). İdiopatik (primer) adeziv kapsülitte genellikle konservatif tedaviye iyi yanıt vardır; hastalar 1-3 yıl arasında iyileşir. Glenohumeral kortikosteroid enjeksiyonu özellikle hastalığın erken dönemlerinde uygulanırsa, semptomları iyileştirebilir. Çoğunda yıllar içerisinde bir miktar hareket kısıtılı̆̆ı kalır ama fonksiyonel kısıtlılık olmaz. Tedavi seçenekleri arasında, fizik tedavi, artroskopik veya açık gevşetme ve denetimli ihmal (Supervised neglect = hastalığın doğal seyrinin açıklanması, ağrı oluşturan egzersizlerin yapılmaması, ağrı oluşturmayacak şekilde aktif ve sarkaç egzersizlerinin yapılması; aktivitelerin tolere edilebilir ölçüde yapılması) mevcuttur (28). Kazanılmış (sekonder) adeziv kapsülit ise; cerrahi veya travma sonrası uzun süreli immobilizasyon nedeniyle gelişir; tedavi genellikle cerrahidir (28).

\section{Romatoid Artrit}

Romatoid artrit (RA) genel toplumda prevalansı \%0,5-1 olan ve kadınlarda daha sık görülen kronik inflamatuar bağ doku hastalığıdır (29). RA'da omuz tutulumu sıklığı \%60-90 olup; omuzu en sık tutan enflamatuar artrittir (29). 5 yılın üzerinde RA tanısı olan hastalarda omuz ağrısı \%90 oranındadır, \%45'inde bilateral anormallik vardır (29). Omuz kuşağı; ağrı nedeniyle genel sağlığı en çok bozan eklemdir. Eklem dışı yapılar da ağrılıdır.

Görüntülemede; erken evrede, osteopeni, kist, glenoid erozyonlar; geç evrede eklem mesafesinde daralma vardır (30). Glenohumeral eklemde \%48 oranında erozif değişikliklere rastlanır (30). Büyük tuberositasta erozyon (periartiküler invazyon) mevcuttur (30). Ayrıca \%75 oranında rotator kaf semptomu, \%20-35 oranında rotator kafta tam kalınlıkta yırtık, rice body ve bursit vardır (30). Rice-body, inflamasyona nonspesifik yanıt olarak gelişir, RA, AS ve TBC artritinde görülür. Intra-artiküler veya intra-bursal olarak gelişebilir; MRG ile tespit edilebilmesi önemlidir, cerrahi olarak eksizyonu ile semptomlarda ciddi düzelme görülür. RA'da büyük tuberositasta tahribatın derinliği (erozyon ve radyolusans) Tanaka ve ark. tarafından hafif, orta ve şiddetli olarak derecelendirilmiştir (31) (Şekil 12). En sıklıkla kullanılan sınıflama ise Larsen tarafından geliştirilmiş olan sınıflamadır ve lezyon şiddetinin derecesine göre 6 evresi mevcuttur (Tablo 2).

Illeri evre RA'da, radiografik eklem hasarı klinik instabiliteye 
yol açar, şiddetli ağrı ve fonksiyonlarda kısıtlanma ortaya çıkar. Böyle durumda total omuz replasmanı gerekir (31). Artroplasti çok geç evrelere bırakılmamalıdır çünkü, glenoid lezyonları ileri evrede olanlarda glenoid kap yerleştirilmesi oldukça zordur ve uygulama sonrasında uzun dönem takiplerde, omuz elevasyonu ve kas gücünde giderek azalma olduğu bildirilmiştir.

\section{Çıkar Çatışması:}

Yazarlar herhangi bir çıkar çatışması bildirmemişlerdir.

\section{Kaynaklar}

1. Hurov J. Anatomy and mechanics of the shoulder: review of current concepts. J Hand Ther 2009;22:328-43.

2. Kanatli U, Bölükbaşi $\mathrm{S}$, Ekin $\mathrm{O}$, Simşek $\mathrm{A}$. Anatomy, biomechanics, and pathophysiology of instability of the glenohumeral joint. Acta Orthop Traumatol Turc 2005;39(Suppl 1):4-13.

3. Snyder SJ, Banas MP, Karzel RP. An analysis of 140 injuries to the superior glenoid labrum. J Shoulder Elbow Surg 1995;4:243-8.

4. Kerr R, Resnick D, Pineda C, Haghighi P. Osteoarthritis of the glenohumeral joint: a radiologic-pathologic study. Am J Roentgenol 1985;144:967-72.

5. Millett PJ, Gobezie R, Boykin RE. Shoulder osteoarthritis: diagnosis and management. Am Fam Physician 2008;78:605-11.

6. Farid N, Bruce D, Chung CB Miscellaneous conditions of the shoulder: anatomical, clinical, and pictorial review emphasizing potential pitfalls in imaging diagnosis. Eur J Radiol. 2008;68:88-105.

7. Gerber A, Lehtinen JT, Warner JJ. Glenohumeral osteoarthritis in active patients: diagnostic tips and complete management options. Phys Sportsmed. 2003;31:33-40.

8. Gomoll AH, Katz JN, Warner JJ, Millett PJ Rotator cuff disorders: recognition and management among patients with shoulder pain. Arthritis Rheum 2004;50:3751-61.

9. Rockwood CA, Matsen FA, Wirth MA, Harryman DT. The Shoulder.2nd ed. Philedelphia, Pa:Saunders; 1998. P. 840-964.

10. Brox JI, Lereim P, Merckoll E, Finnanger AM. Radiographic classification of glenohumeral arthrosis. Acta Orthop Scand 2003;74:186-9.

11. Walch G, Badet R, Boulahia A, Khoury A.Morphologic study of the glenoid in primary glenohumeral osteoarthritis. I Arthroplasty 1999;14:756-60.

12. Nowak DD, Gardner TR, Bigliani LU, Levine WN, Ahmad CS. Interobserver and intraobserver reliability of the Walch classification in primary glenohumeral arthritis. J Shoulder Elbow Surg 2010;19:180-3.

13. Nové-Josserand L, Walch G, Adeleine P, Courpron P. Effect of age on the natural history of the shoulder: a clinical and radiological study in the elderly). Rev Chir Orthop Reparatrice Appar Mot 2005;91:508-14.

14. Feeley BT, Gallo RA, Craig EV.Cuff tear arthropathy: current trends in diagnosis and surgical management. I Shoulder Elbow Surg 2009;18:484-94.

15. Neri BR, Chan KW, Kwon YW. Management of massive and irreparable rotator cuff tears. J Shoulder Elbow Surg 2009;18:808-18.
16. Gerber C, Wirth SH, Farshad M. Treatment options for massive rotator cuff tears. J Shoulder Elbow Surg 2011;20(2 Suppl):20-9.

17. Sirveaux F, Favard L, Oudet D, Huquet D, Walch G, Molé D. Grammont inverted total shoulder arthroplasty in the treatment of glenohumeral osteoarthritis with massive rupture of the cuff. Results of a multicentre study of 80 shoulders. J Bone Joint Surg Br 2004;86:388-95.

18. Saccomanni B. Inflammation and shoulder pain--a perspective on rotator cuff disease, adhesive capsulitis, and osteoarthritis: conservative treatment. Clin Rheumatol 2009;28:495-500.

19. Orfaly RM, Rockwood CA Jr, Esenyel CZ, Wirth MA. Shoulder arthroplasty in cases with avascular necrosis of the humeral head. J Shoulder Elbow Surg 2007;16(3 Suppl):27-32.

20. Gruson KI, Kwon YW. Atraumatic Osteonecrosis of the Humeral Head. Bull NYU Hosp Jt Dis 2009;67:6-14.

21. Wolfe CJ, Taylor-Butler KL. Avascular necrosis: A Case history and literature Review. Arch Fam Med 2000;9:291-4.

22. Uribe JW, Botto-van Bemden A. Partial humeral head resurfacing for osteonecrosis. J Shoulder Elbow Surg 2009;18:711-6.

23. Noain E, Martínez de Morentín J, Artázcoz F], Gozzi S, Lasanta P, SánchezVillares JJ. Neuropathic arthropathy of the shoulder. An Sist Sanit Navar 2007;30:487-90.

24. Ryu JD, Kirpalani PA, Kim JM, Nam KH, Han CW, Han SH. Expression of vascular endothelial growth factor and angiogenesis in the diabetic frozen shoulder. J Shoulder Elbow Surg 2006;15:679-85.

25. Ozaki J, Nakagawa Y, Sakurai G, Tamai S. Recalcitrant chronic adhesive capsulitis of the shoulder. Role of contracture of the coracohumeral ligament and rotator interval in pathogenesis and treatment. J Bone Joint Surg Am 1989;71:1511-5.

26. Carbone S, Gumina S, Vestri AR, Postacchini R . Coracoid pain test: a new clinical sign of shoulder adhesive capsulitis. Int Orthop 2010;34:385-8.

27. Walmsley S, Rivett DA, Osmotherly PG. Adhesive capsulitis: establishing consensus on clinical identifiers for Stage 1 Using the DELPHI Technique. Phys Ther 2009;89:906-17.

28. Diercks RL, Stevens M. Gentle thawing of the frozen shoulder: a prospective study of supervised neglect versus intensive physical therapy in seventy-seven patients with frozen shoulder syndrome followed up for two years. J Shoulder Elbow Surg 2004;13:499-502.

29. Hambright D, Henderson RA, Cook C, Worrell T, Moorman CT, Bolognesi MP. A comparison of perioperative outcomes in patients with and without rheumatoid arthritis after receiving a total shoulder replacement arthroplasty. J Shoulder Elbow Surg 2011;20:77-85.

30. Holcomb JO, Hebert DJ, Mighell MA, Dunning PE, Pupello DR, Pliner MD, et al. Reverse shoulder arthroplasty in patients with rheumatoid arthritis. J Shoulder Elbow Surg 2010;19:1076-84.

31. Tanaka H, Sugamoto K, Sahara W, Ono T, Tomita T, Hashimoto J.et al. The mode of destruction in shoulders with rheumatoid arthritis based on radiographic findings. J Shoulder Elbow Surg 2007;16:539-43. 